\title{
Syringe Pump With Nearly Empty Indicator Based on Microcontroller Atmega328
}

\author{
Lely Erica Putri, M. Ridha Mak'ruf, Abd. Kholiq \\ Department of Electromedical Engineering PoltekkesKemenkes, Surabaya \\ Jl. Pucang Jajar Timur No. 10, Surabaya, 60245, Indonesia \\ lelyericaputri@gmail.com,m.reedha@gmail.com,kawullah@gmail.com
}

\begin{abstract}
Syringe Pump is a tool used to give liquid medicine or food liquid into the patient's body in a certain amount and within a certain period of time on a regular basis. The purpose of this study is to facilitate the monitoring of fluid in the syringe so that the hose is not installed continuously when the liquid has run out. The circuit consists of an Atmega328 microcontroller, a motor driv er, and an optocoupler sensor. Setting the syringe, volume and flowrate are done at the beginning. To insert liquid, the motor must be run by the way the settings have been done and press the start button. Tools need supply from PLN grids. Calibration is done using IDA 4 Plus. This tool is equipped with the addition of alarms nearly empty and the bolus button. From the measurements taken, at the $20 \mathrm{ml}$ syringe, the biggest error occurred at the $5 \mathrm{ml}$ volume point of $0.4 \%$ and at the $50 \mathrm{ml}$ syringe the biggest error occurred at the $5 \mathrm{ml}$ volume point of $0.280 \%$. This module can be used according to its function because the\% error is still below the $\pm 5 \%$ standard.
\end{abstract}

Keywords-Syringe Pump; Driver Motor; Optocoupler

\section{INTRODUCTION}

The hospital is a very complex system so it is difficult to control every patient. For patients who need extra and intensive treatment, we need a tool that can control the dosage of drug use volume and flowrate to be injected. Flowrate is the amount of fluid flowing per unit time. The medical device that can automatically inject is a syringe pump. In this case, the nurse only gives input on the tool in the form of the volume of drugs needed and flowrate which is conditioned by the patient's needs. A syringe pump is one of the electromedical equipment that functions to insert the liquid medicine into the patient's body within a certain period of time on a regular basis. A syringe pump is a drug that is inserted in a syringe that is inserted into the body through veins. In the syringe itself, there are several parameters, namely the amount of volume and flow rate. In this case, the nurse only gives input to the tool in the form of the volume of drug needed and flowrate which is conditioned by the patient's need to get the volume of drug per hour (ml/hour)[1] [2]. In some cases of patients such as hypertension before surgery, heart disease, and neurological diseases, the administration of liquid drugs must be carried out intensively, namely, the fluid volume of the drug must be at a constant flow rate. In patients with critical conditions, intensive care is needed in order to avoid fluid imbalance in the body[3]. The drug fluid is inserted into the patient's body through intravenous injection for a long duration with flowrate adjusted to the right level so that a syringe can be programmed automatically. A syringe pump is a medical device that is used to inject liquid drugs continuously with therapeutic and diagnostic purposes[4] [5].
In this case, the module to be created is equipped with an alarm nearly empty. This alarm is an indication of the volume of drugs approaching the syringe pump. This alarm is a marker that the volume will run out so the nurse can approach the device so that the hose is not installed continuously when the volume has run out. This nearly empty alarm will sound 3 minutes before the volume of liquid runs out. The alarm will sound for the last 3 minutes and turn off when the volume is up [6].

In 2006 Siti Maghfiroh conducted research entitled "Syringe Pump based on the ATmega89S51 microcontroller". The advantages of this research are the mechanics used to design it themselves. The disadvantage of this study is that it still uses 1 syringe, which is $50 \mathrm{ml}$ size and uses $10 \mathrm{ml} /$ hour flow rate. In 2011 Sheindy Chandra Kusumawati conducted a study entitled "Dual Spuit Syringe Pump". The advantage of this study is to use 2 kinds of syringe sizes of $20 \mathrm{ml}$ and $50 \mathrm{ml}$ and the flow rate used is $10 \mathrm{ml} /$ hour and $20 \mathrm{ml} /$ hour. The disadvantage of this study is that the error value is still very high so that at $5 \mathrm{ml}$ volume it cannot be used. In 2013 Meinar Dwi Anggraeni conducted research entitled "Portable Syringe Pump". The advantage of this research is that it is portable, no longer requires PLN grids but uses batteries. The disadvantage of this study is that battery life lasts only 1 hour. In 2018 Faizatul Rosyidah conducted a study entitled "Monitoring of Drip Infuse Pump and Syringe Pump". The advantage of this research is that it can monitor the fluid injected through a PC. The disadvantage of this study is the absence of additional boluses and safety indicators in patients.

Based on the identification of the problems above, the author intends to design a syringe pump equipped with nearly 
empty based atmega328 microcontroller which can be used as a reminder 3 minutes before the liquid runs out so that the hose is not continuously attached to the patient's body when the liquid has run out.

\section{MATERIALS AND METHODS}

\section{A. Experimental Setup}

This study uses two syringes of size $20 \mathrm{ml}$ and $50 \mathrm{ml}$. The volume used starts from $5 \mathrm{ml}$ to $50 \mathrm{ml}$ with an increase of every $5 \mathrm{ml}$ and with 4 different types of flowrate at different speeds. Retrieval of the data is done 5 times.

\section{1) Materials and Tool}

This study uses an original stepper motor from a B Broun syringe to drive fluid in the syringe and optocoupler sensor to calculate motor rotation. The components used include Atmega328 as a microcontroller, a motor driver to drive the motor and a $4 \times 16$ LCD as a display.

\section{2) Experiment}

In this study, the measurement of the motor driver circuit was carried out by using an oscilloscope. This measurement aims to see the output of the motor driver with a different flowrate setting so that the different frequency and period values are obtained for each flow rate. The researcher also conducted data retrieval using an IDA 4 Plus calibrated tool to calibrate the volume and flowrate made by the researcher.

\section{B. The Diagram Block}

When the device is turned on the MCU or microcontroller will wait for the command from the settings to run the motor. The settings needed are syringe settings, volume settings, and flowrate settings. All settings will be displayed on the display. The microcontroller will instruct the motor driver to run the motor and push the syringe. The optocoupler circuit here serves to calculate the number of turns of the motor that is used as a reference for the microcontroller input and convert it to $\mathrm{ml}$ units to be used to calculate the remaining volume. If 3 minutes before the liquid runs out, the buzzer will ring. When the volume runs out the motor will stop working.

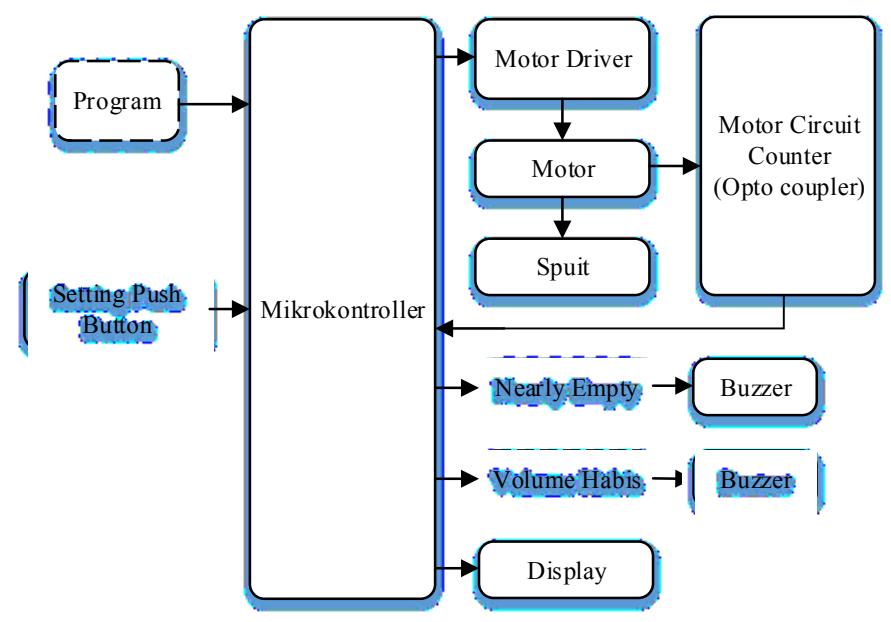

Fig. 1. Diagram Block

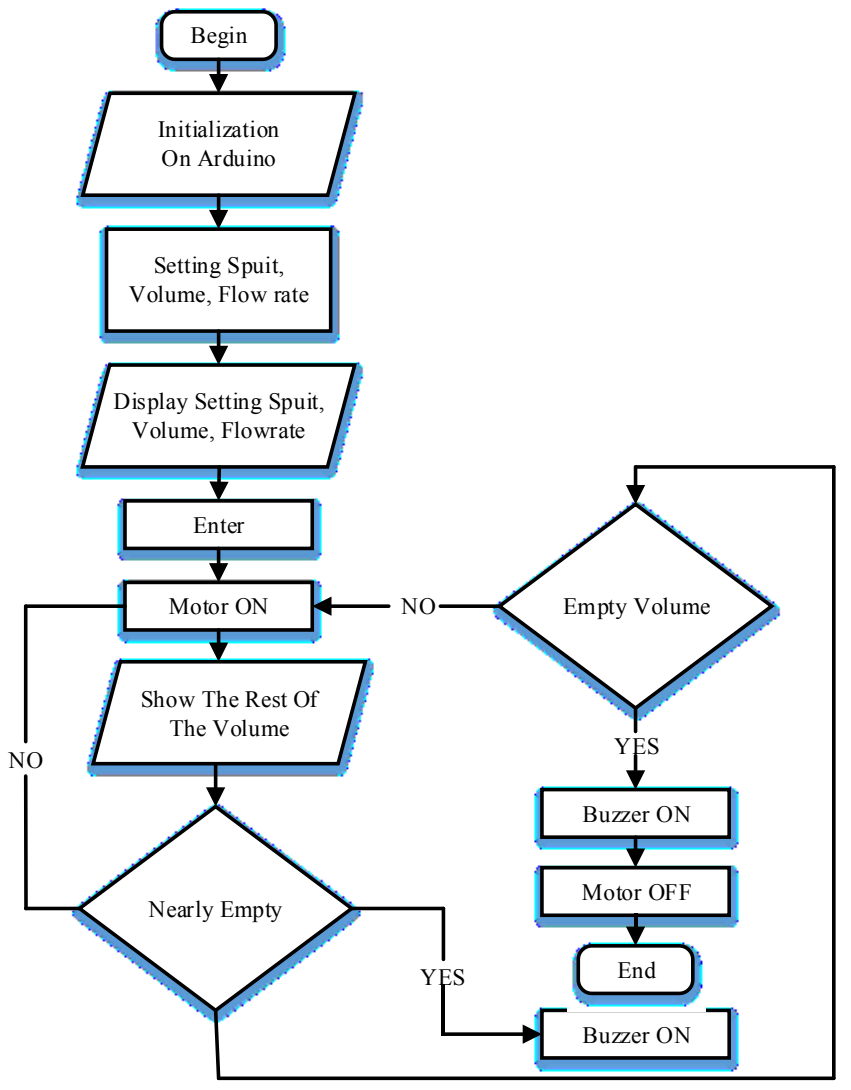

Fig. 2. Flowchart of the Arduino Program

\section{The Flowchart}

When the tool is turned on the tool initializes it first. After setting the syringe, volume $(\mathrm{ml})$ and flow rate $(\mathrm{ml} /$ hour$)$. The results of the settings will be displayed on the display, then press start to run the motor. After that, the display will display the remaining volume. If the volume approaches nearly empty, then the buzzer will sound. The buyer will sound 3 minutes before the volume runs out. The buzzer will sound until the volume has run out and the motor will stop working.

\section{The Analog Circuit}

The important part of this tool is the analog circuit illustrated in Fig. 3 (optocoupler), Fig. 4 (motor driver).

1) Optocoupler

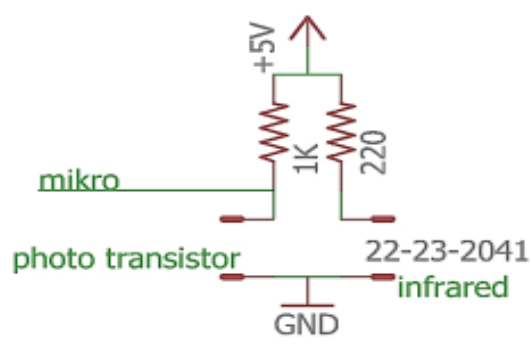

Fig. 3. Optocoupler Circuit 
The Optocoupler circuit is shown in Fig. 3 consists of transistor photos and infrared. Where when there is an object that is between the sensor gap, the transmitted light cannot be received by the receiving party, so that it produces an output voltage whose value is close to $\mathrm{VCC}$ which is $5 \mathrm{~V}$. If there is no object between the sensor slits it will produce an output voltage whose value is close to $0 \mathrm{~V}$.

\section{2) Motor Driver}

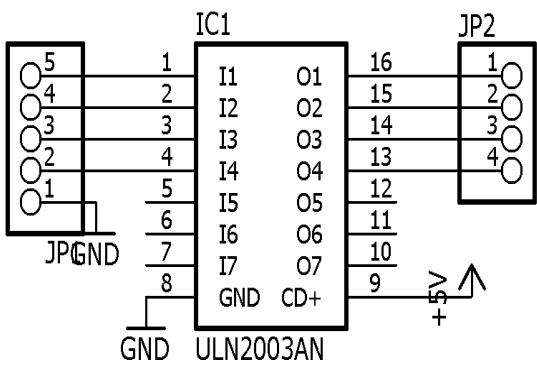

Fig. 4. Motor Driver Circuit

The motor driver circuit shown in Fig. 4 uses the ULN 2003 IC. There are 4 inputs that will be connected to the microcontroller circuit and 4 outputs to enter the stepper motor. This driver serves to drive the motorbike driver using logic inputs with varying loop settings as needed. This driver will switch the output logic of the microcontroller to the motor pin alternately.

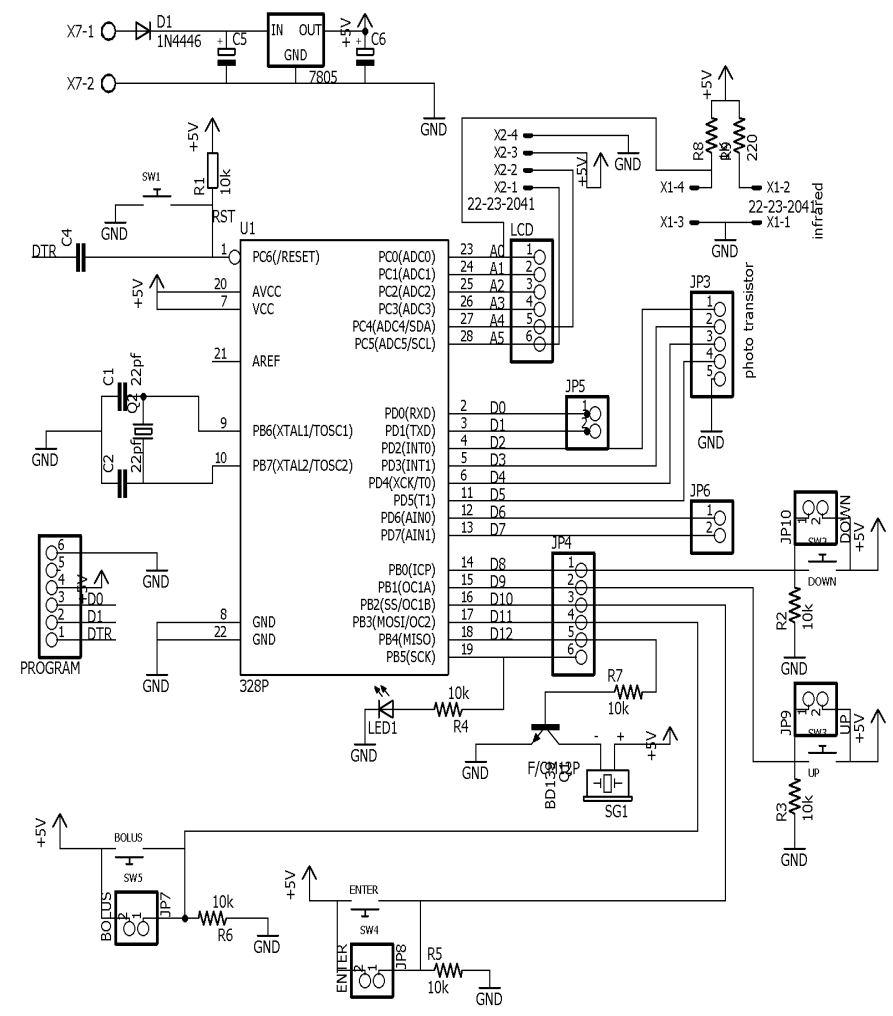

Fig. 5. Microcontroller
The microcontroller circuit shown in fig.5 is used for processing data from the motor driver and optocoupler outputs. The optocoupler sensor will enter the pin A0 and the motor driver enters the digital pin 2.

\section{RESULTS}

In this study, trials have been carried out on the tool directly by using syringes 2 different sizes and the results set with the output will be seen in the measuring cup. The researcher also took measurements using the syringe pump calibrator, IDA 4 Plus as a comparison.

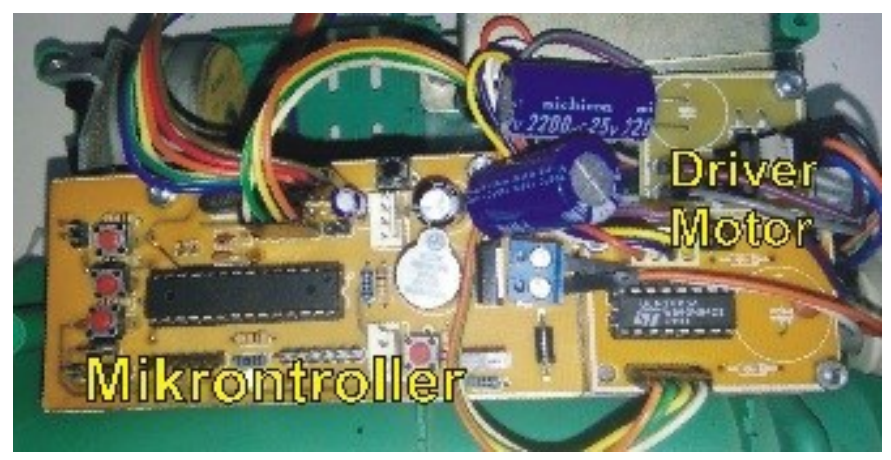

Fig. 6. Module Design

\section{1) TheModul Design}

The photo section of the microcontroller and motor driver of this tool is shown in Fig. 6. Parts of the microcontroller which consists of Atmega328 as a system regulator, crystal $16,000 \mathrm{MHz}$ which functions as an external clock to carry out the functions of the microcontroller. In the motor driver, there is a ULN2003 IC that drives the motor so the motor can rotate.

\section{2) The Listing Program for Arduino}

Arduino program listing consists of the initial setting program (selection of syringes, volume settings, and flowrate settings) shown in Program Listing 1, the program for setting the flowrate value shown in Program Listing 2, and the program calculating the remaining volume shown in Program Listing 3.

Listing program 1. Program to Initial Setting

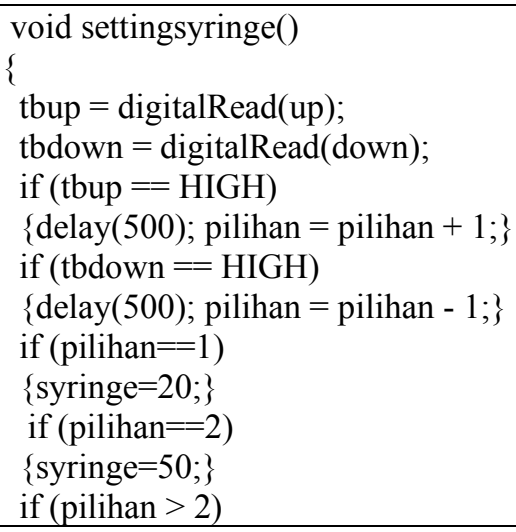




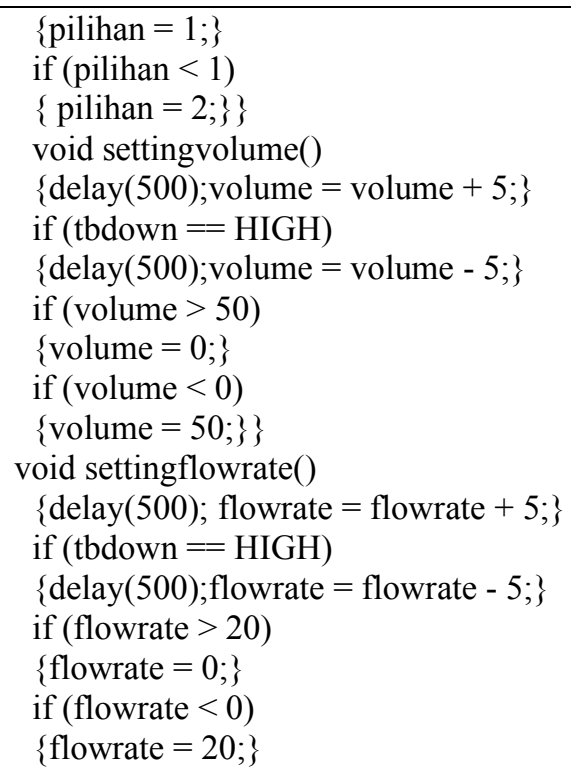

Listing Program 2. Program to Setting the Flowrate Value

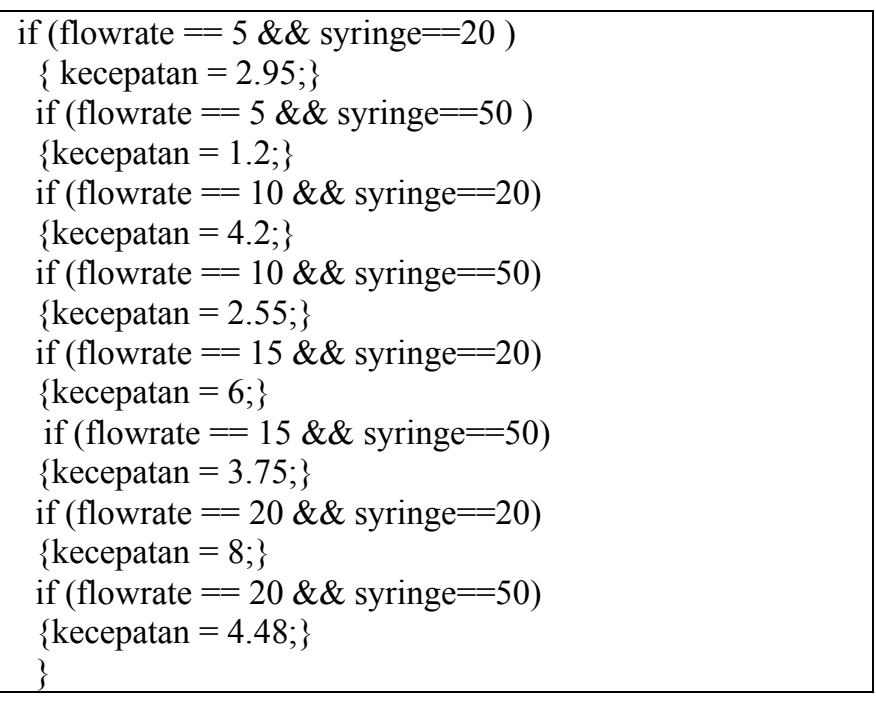

Listing Program 3. Program to count the remaining volume

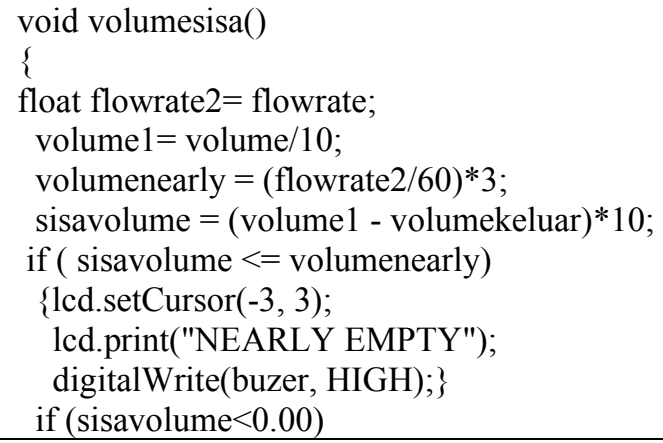

$\{$ motordiam ()$;\}\}$

3) Measurement of Output Circuit of Motor Driver on Oscilloscope

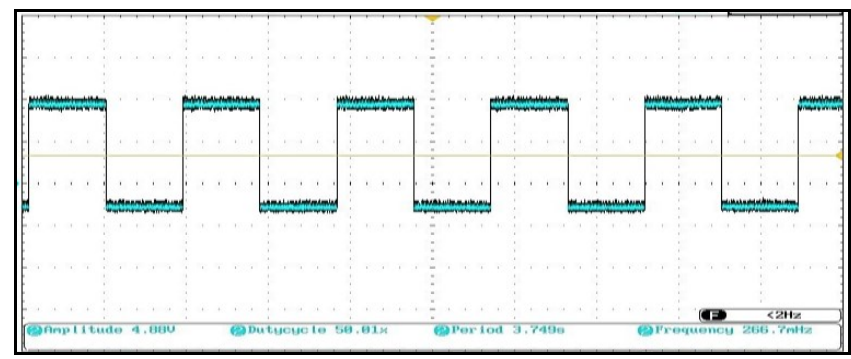

Fig. 7. The output from ATmega328 pin at a flow rate of $5 \mathrm{ml} /$ hour

Based on the picture above, the ATmega 328 pin 4 output can see an output with an amplitude of $4.88 \mathrm{~V}$, a $50 \%$ duty cycle with a frequency of $266.7 \mathrm{MHz}$ with a period of $3,750 \mathrm{~s}$. TON results obtained at $50 \%$ and TOFF results obtained at $50 \%$. In the condition of the $\mathrm{TON}$, the motor driver gets high logic, the motor will work while in the TOFF condition the motor driver gets a low logic, and the motor will stop.

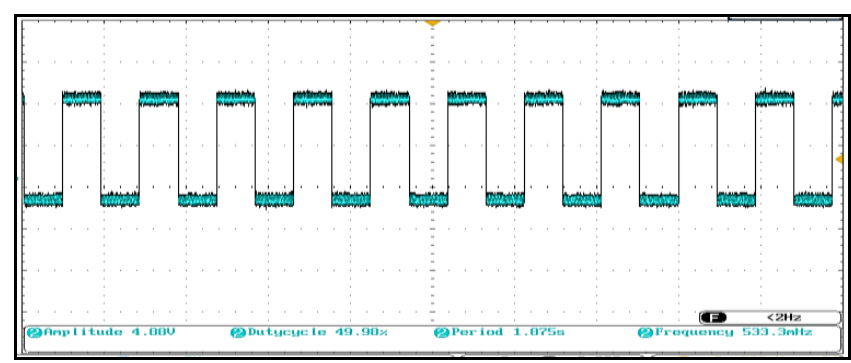

Fig. 8. The output from ATmega328 pin at a flow rate of $10 \mathrm{ml} /$ hour

Based on the picture above, the ATmega 328 pin 4 output can see an output with an amplitude of $4.88 \mathrm{~V}$, a duty cycle of $50.03 \%$ with a frequency of $533.3 \mathrm{MHz}$ with a period of 1,875 s. The TON results obtained were $50.03 \%$ and the TOFF results were obtained at $49.97 \%$. In the condition of the TON, the motor driver gets high logic, the motor will work while in the TOFF condition the motor driver gets a low logic, and the motor will stop.

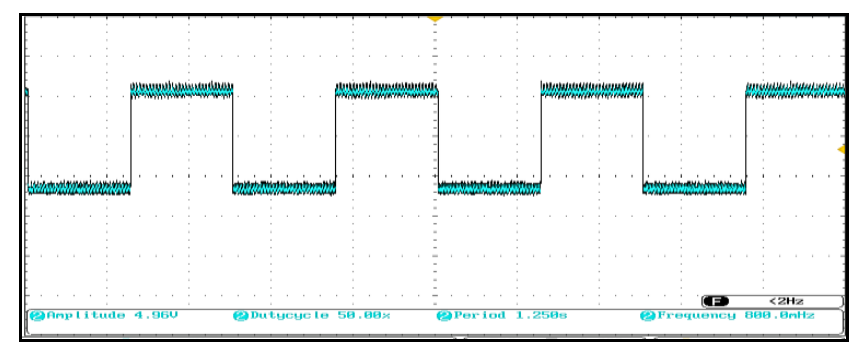

Fig. 9. Output from ATmega328 pin at a flow rate of $15 \mathrm{ml} /$ hour

Based on the picture above at the ATmega 328 pin 4 output can be seen output with an amplitude of $4.96 \mathrm{~V}$, a $50 \%$ 
duty cycle with a frequency of $800 \mathrm{MHz}$ with a period of $1,250 \mathrm{~s}$. TON results obtained at $50 \%$ and TOFF results obtained at $50 \%$. In the condition of the TON, the motor driver gets high logic, the motor will work while in the TOFF condition the motor driver gets a low logic, and the motor will stop.

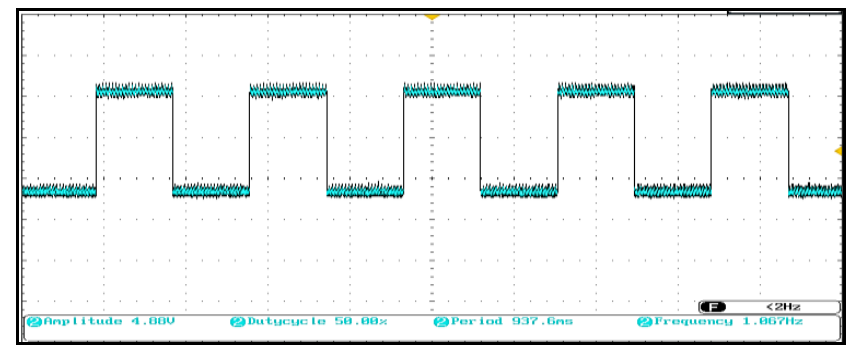

Fig. 10. The output from ATmega328 pin at a flow rate of $20 \mathrm{ml} /$ hour

Based on the picture above at the ATmega 328 pin 4 output can be seen output with an amplitude of $4.88 \mathrm{~V}$, a $50 \%$ duty cycle with a frequency of $1.067 \mathrm{~Hz}$ with a period of $937.6 \mathrm{~ms}$. TON results obtained at $50 \%$ and TOFF results obtained at $50 \%$. In the condition of the TON, the motor driver gets high logic, the motor will work while in the TOFF condition the motor driver gets a low logic, and the motor will stop.

4) The Error of Volume $(\mathrm{ml})$ Value

The volume measurement results in each set are measured by the IDA 4 Plus tool. The error value is shown in Table I.

TABLE I. THE ERROR OF MEASUREMENT FOR VOLUME SETTINGS 20 ML SPUIT

\begin{tabular}{ccc}
\hline No & Volume $(\mathrm{ml})$ & Error $(\%)$ \\
\hline 1 & 5 & 0,4 \\
2 & 10 & 0,14 \\
3 & 15 & 0,013 \\
4 & 20 & 0,030 \\
5 & 25 & 0,056 \\
6 & 30 & 0,007 \\
7 & 35 & 0,040 \\
8 & 40 & 0,030 \\
9 & 45 & 0,022 \\
10 & 50 & 0,052 \\
\hline
\end{tabular}

TABLE II. THE ERROR OF MEASUREMENT FOR FLOW RATE SETTINGS ON 20 ML SPUIT

\begin{tabular}{ccc}
\hline No & $\begin{array}{c}\text { Flow Rate } \\
(\mathrm{ml} / \text { hour })\end{array}$ & Error $(\%)$ \\
\hline 1 & 5 & 0,32 \\
2 & 10 & 0,2 \\
3 & 15 & 0,05 \\
4 & 20 & 0,1 \\
5 & 75 & 0,01 \\
\hline
\end{tabular}

TABLE III. THE ERROR OF MEASUREMENT FOR VOLUME SETTINGS ON 50 ML SPUIT

\begin{tabular}{ccc}
\hline No & Volume $(\mathrm{ml})$ & Error $(\%)$ \\
\hline 1 & 5 & 0,280 \\
2 & 10 & 0,260 \\
3 & 15 & 0,067 \\
4 & 20 & 0,040 \\
5 & 25 & 0,016 \\
6 & 30 & 0,00 \\
7 & 35 & 0,034 \\
8 & 40 & 0,050 \\
9 & 45 & 0,009 \\
10 & 50 & 0,004 \\
\hline
\end{tabular}

TABLE IV. THE ERROR OF MEASUREMENT FOR FLOW RATE SETTINGS ON 20 ML SPUIT

\begin{tabular}{ccc}
\hline No & $\begin{array}{c}\text { Flow Rate } \\
(\mathrm{ml} / \text { hour })\end{array}$ & Error $(\%)$ \\
\hline 1 & 5 & 0,16 \\
2 & 10 & 0,10 \\
3 & 15 & 0,027 \\
4 & 20 & 0,090 \\
5 & 75 & 0,061 \\
\hline
\end{tabular}

\section{DISCUSSION}

The difference in the selection of flowrate can affect the frequency and period of the microcontroller output signal which can be seen through an oscilloscope. Calculation of the average error with a $20 \mathrm{ml}$ syringe is $=0.09 \%$ and with a $50 \mathrm{ml}$ syringe value $=0.085 \%$. Errors can be caused because the mechanical motor used is less stable, the voltage at the supply decreases and the reading resolution is high. On ECRI's provisions about the maximum permissible errors in the syringe pump which is equal to $5 \%$, so the syringe pump module is equipped with nearly empty microcontroller ATmega 328 worthy of use.

\section{Conclusion}

Based on the results of the discussion and the purpose of making the module it can be concluded that after volume measurement using a $20 \mathrm{ml}$ syringe, the smallest error occurred at $30 \mathrm{ml}$ volume point of $0.007 \%$ and the biggest error occurred at $5 \mathrm{ml}$ volume point of $0.4 \%$. Volume measurement using $50 \mathrm{ml}$ syringe, the smallest error occurred at $30 \mathrm{ml}$ volume point of $0 \%$ and the biggest error occurred at $5 \mathrm{ml}$ volume point of $0.280 \%$. Software to run a minimum series of microcontroller systems in running well so that it can run the tool according to the settings. The tool can work well because the biggest error value is $0.4 \%$ while the maximum error allowed is $5 \%$. 


\section{References}

[1] K. K. Tulungagung, "ADLN Perpustakaan Universitas Airlangga 1," pp. $1-8,2017$.

[2] Y. C. Yu, "Automatic monitoring of the infusion system in a rotary heart assist device," in Proceedings of the IEEE Annual Northeast Bioengineering Conference, NEBEC, 2003, vol. 2003-Janua, pp. 116117.

[3] F. R. Halim, Suwandi, and A. Suhendi, "Rancang Bangun Syringe Pump menggunakan Motor Stepper Berbasis Arduino," e-Proceeding Eng., vol. 3, no. 2, pp. 2078-2085, 2016.

[4] I. Saidi, L. ElAmraoui, and M. Benrejeb, "Multi-physics modeling of a linear tubular step actuator," Int. Rev. Model. Simulations, vol. 3, no. 6, pp. 1202-1208, 2010.

[5] G. Cocha, J. Rapallini, O. Rodriguez, C. Amorena, H. Mazzeo, and C. E. Drattellis, "Intelligent Insulin Pump Design," in Congreso Argentino de Ciencias de la Informatica y Desarrollos de Investigacion, CACIDI 2018, 2018, pp. 7-10.

[6] M. Deepalakshmi and R. Jayaparvathy, "Design and implementation of a lowcost Integrated Insulin Infusion system," in 2016 International Conference on Computation of Power, Energy, Information and Communication, ICCPEIC 2016, 2016, pp. 25-32. 